\title{
Stimulus Feature Selectivity in Excitatory and Inhibitory Neurons in Primary Visual Cortex
}

\author{
Jessica A. Cardin, Larry A. Palmer, and Diego Contreras \\ Department of Neuroscience, University of Pennsylvania School of Medicine, Philadelphia, Pennsylvania 19106
}

\begin{abstract}
Although several lines of evidence suggest that stimulus selectivity in somatosensory and visual cortices is critically dependent on unselective inhibition, particularly in the thalamorecipient layer 4, no comprehensive comparison of the responses of excitatory and inhibitory cells has been conducted. Here, we recorded intracellularly from a large population of regular spiking (RS; presumed excitatory) and fast spiking (FS; presumed inhibitory) cells in layers 2- 6 of primary visual cortex. In layer 4, where selectivity for orientation and spatial frequency first emerges, we found no untuned FS cells. Instead, the tuning of the spike output of layer 4 FS cells was significantly but moderately broader than that of RS cells. However, the tuning of the underlying synaptic responses was not different, indicating that the difference in spike-output selectivity resulted from differences in the transformation of synaptic input into firing rate. Layer $4 \mathrm{FS}$ cells exhibited significantly lower input resistance and faster time constants than layer $4 \mathrm{RS}$ cells, leading to larger and faster membrane potential $\left(V_{\mathrm{m}}\right)$ fluctuations. FS cell $V_{\mathrm{m}}$ fluctuations were more broadly tuned than those of RS cells and matched spike-output tuning, suggesting that the broader spike tuning of these cells was driven by visually evoked synaptic noise. These differences were not observed outside of layer 4 . Thus, cell type-specific differences in stimulus feature selectivity at the first level of cortical sensory processing may arise as a result of distinct biophysical properties that determine the dynamics of synaptic integration.
\end{abstract}

Key words: intracellular; orientation; spatial frequency; synaptic noise; tuning; time constant

\section{Introduction}

The responses of cortical cells to sensory stimuli depend critically on the interactions between excitatory and inhibitory inputs. Particularly in the thalamorecipient cortical layer 4, studies in vivo have shown that both the selectivity (Wehr and Zador, 2003; Wilent and Contreras, 2005b) and timing (Higley and Contreras, 2006) of cortical responses to sensory input are determined by the relative timing and amplitude of inhibitory and excitatory inputs. In the primary visual cortex, this interplay between excitation and inhibition is a critical element of the receptive field structure of simple cells (Anderson et al., 2000a; Monier et al., 2003; Marino et al., 2005) and, consequently, of stimulus selectivity (Jones et al., 1987; Lampl et al., 2001; Monier et al., 2003). Moreover, local inhibitory input in primary visual cortex has been implicated in maintaining constant orientation and spatial frequency selectivity during changes in stimulus contrast (Somers et al., 1995; Troyer et al., 1998; Lauritzen and Miller, 2003).

Intracellular studies in primary visual cortex in vivo have used the tuning properties of excitatory and inhibitory postsynaptic potentials (Ferster, 1986, 1987, 1988; Anderson et al., 2000a; Hirsch, 2003; Monier et al., 2003) to infer the tuning properties of presynaptic excitatory and inhibitory cells. Based on these inferHigley for helpful comments on a previous version of this manuscript and Dr. Esther Garcia de Yebenes for histology. Correspondence should be addressed to Diego Contreras, Department of Neuroscience, University of Pennsylvania School of Medicine, 215 Stemmler Hall, Philadelphia, PA 19106-6074. E-mail: diego@@mail.med.upenn.edu. DOI:10.1523/JNEUROSCI.1692-07.2007

Copyright $\odot 2007$ Society for Neuroscience $\quad$ 0270-6474/07/2710333-12\$15.00/0 ences, a variety of strategies have been proposed by which excitatory and inhibitory inputs may contribute to the emergence of stimulus selectivity. However, the tuning of postsynaptic excitation and inhibition does not necessarily reflect the properties of individual presynaptic cells. Rather, it is strongly dependent on both patterns of synaptic convergence and the relative degree of recurrent activation of excitation and inhibition. Although there is some evidence for broadly tuned interneurons in layer 4 (Azouz et al., 1997; Hirsch et al., 2002, 2003; Usrey et al. 2003), it is not clear whether inhibitory and excitatory neurons comprise two populations with distinct degrees of stimulus selectivity. Furthermore, if systematic tuning differences exist between excitatory and inhibitory cells, they may derive either from differences in synaptic input or from differences in the intrinsic transformation of synaptic input to spike output.

Here we use intracellular recordings in cat primary visual cortex in vivo to compare the stimulus selectivity of two classes of cells: fast spiking (FS) inhibitory interneurons and regular spiking (RS) excitatory projection neurons (Connors et al., 1982; Kawaguchi and Kubota, 1993; Nowak et al., 2003). We find that layer 4 RS and FS cells demonstrate statistically indistinguishable tuning for stimulus orientation and spatial frequency at the level of synaptic responses, but FS cells show significantly broader spike-response tuning than RS cells. In contrast, we find no difference in the synaptic or spike tuning of RS and FS cells outside layer 4 . Within layer 4 , differences in visually evoked membrane potential $\left(V_{\mathrm{m}}\right)$ fluctuations and distinct biophysical properties account for these differences in stimulus selectivity. Together, our results suggest that the differing sensory response properties of RS and FS cells in layer 4 result, in part, from biophysical 
membrane properties. These results constrain previously proposed models of both the stimulus selectivity and the contrast invariance of cortical visual responses.

\section{Materials and Methods}

Surgical protocol. Experiments were conducted in accordance with the guidelines of the National Institutes of Health and with the approval of the Institutional Animal Care and Use Committee of the University of Pennsylvania. Surgical and recording methods were as reported previously (Contreras and Palmer, 2003; Cardin et al., 2005). Briefly, adult cats $(2.5-3.5 \mathrm{~kg})$ were anesthetized with an initial intraperitoneal injection of thiopental $(25 \mathrm{mg} / \mathrm{kg})$ and supplementary halothane $(2-4 \%$ in a $70: 30$ mixture of $\mathrm{N}_{2} \mathrm{O}$ and $\mathrm{O}_{2}$ ). Subsequently, inhalant anesthesia was discontinued, intravenous thiopental was administered, and the animal was paralyzed with gallamine triethiodide (Flaxedil). Anesthesia was maintained during surgery with intravenous thiopental as needed for the duration of the experiment (14-16 h) with a continuous infusion (3-10 $\mathrm{mg} / \mathrm{hr}$ ). Anesthesia level was monitored by continuous recordings of heart rate, blood pressure, and EEG. Because thiopental was infused continuously, we obtained a very stable level of anesthesia throughout the experiment. The end-tidal $\mathrm{CO}_{2}$ was kept at $3.7 \pm 0.2 \%$ and the rectal temperature was kept at $37-38^{\circ} \mathrm{C}$ with a heating pad.

The surface of the visual cortex was exposed with a craniotomy centered at Horsley-Clarke coordinates posterior 4.0, lateral 2.0. The stability of the recordings was improved by performing a bilateral pneumothorax, draining the cisterna magna, suspending the hips, and filling the cranial defect with a solution of $4 \%$ agar. Intracellular recordings were performed with glass micropipettes $(50-80 \mathrm{M} \Omega$ ) filled with $3 \mathrm{~m}$ potassium acetate and 1-2\% neurobiotin. All cells used in this study had a stable $V_{\mathrm{m}}$ more negative than $-60 \mathrm{mV}$, had overshooting action potentials, and were recorded for at least $15 \mathrm{~min}$. For each electrode penetration, we lowered the pipette perpendicular to the surface of the apex of the lateral gyrus. In hundreds of electrode penetrations, we consistently found layer 4 simple cells clustered between 600 and $950 \mu \mathrm{m}$, as measured from the microdrive position. Laminar position was then confirmed post hoc by staining filled cells, and these depths varied from the microdrive values by an average of $\pm 30 \mu \mathrm{m}$. A plot of the depths of the simple and complex cells used in this study is shown in supplemental Figure 1 (available at www.jneurosci.org as supplemental material).

Visual stimulation. The corneas were protected with contact lenses after dilating the pupils with $1 \%$ atropine and retracting the nictitating membranes with phenylephrine (Neosynephrine). Spectacle lenses were chosen by the tapetal reflection technique to optimize the focus of stimuli on the retina. The position of the monitor was adjusted with an $x-y$ stage so that the area centralae were well centered on the screen.

Stimuli were presented on an Image Systems (Minnetonka, MN) model M09 LV monochrome monitor operating at 125 frames per second at a spatial resolution of $1024 \times 786$ pixels and a mean luminance of $47 \mathrm{~cd} / \mathrm{m}^{2}$. Custom software allowed for stimulus control, on-line displays of acquired signals ( $V_{\mathrm{m}}$ and spikes), and a graphical user interface for controlling all stimulus parameters. In addition to this online control, all data were stored on a Nicolet Vision (LDS, Middleton, WI) for off-line analyses. $V_{\mathrm{m}}$ and stimulus marks were sampled at $10 \mathrm{kHz}$ with 16 bit analog-to-digital converters.

Computer-assisted hand plotting routines were used with every cell to provide initial estimates of the optimal orientation, direction of movement, and spatial and temporal frequencies and to determine the receptive field position and dimensions. Tuning curves for orientation and spatial frequency were then determined more precisely with several series of drifting sinusoidal gratings spanning the initial estimates. For broadly tuned cells, orientation was varied in steps of $22.5^{\circ}$. For most cells, orientation was varied in smaller steps around the optimal $( \pm 3, \pm 6, \pm 12$, $\pm 18, \pm 26, \pm 34$, and $\pm 44^{\circ}$ ), providing much finer resolution of the tuning curve. Similarly, spatial frequency tuning was assessed using stimuli whose spatial frequency varied in small steps around the initial estimates. All stimuli in a given series were presented in pseudorandom order. When orientation or spatial frequency was varied, all other parameters of the stimuli, including mean luminance, were held constant.
Cells were classified as simple or complex based on two criteria. First, the relative modulation of spike trains evoked by an optimized patch of drifting sinusoidal grating was measured. If the response at the fundamental temporal frequency of the stimulus (F1) exceeded the average (DC) response, the cell was classified as simple. Otherwise, the cell was classified as complex (Skottun et al., 1987). Second, we estimated the one-dimensional spatiotemporal weighting function by averaging membrane potential and spike responses to bright and dark bars $(n=16)$ distributed across the receptive field at the optimal orientation. Cells exhibiting nonoverlapping regions excited by bright and dark stimuli were classified as simple. Cells showing excitation to bright and dark stimuli throughout their receptive fields were classified as complex. These two measures yielded the same functional classification in every case.

Response quantification. Orientation curves were characterized by the half-width at half height (HWHH) of the best fitted Gaussian function. Bandwidth (BW) of the spatial frequency curves was calculated in octaves as BW $=\log _{2}\left(F_{\text {high }} / F_{\text {low }}\right)$, where $F_{\text {high }}$ and $F_{\text {low }}$ are the upper and lower frequency cutoffs at half-height on the tuning curve, respectively. Cells with low-pass spatial frequency characteristics were not included in population estimates of bandwidth. For $V_{m}$ measurements, spikes were removed by first determining the time at which spike threshold was reached and then extrapolating the $V_{\mathrm{m}}$ values from that point to when the spike repolarized back the spike threshold level. This was followed by smoothing with a three-point running average. The number of spikes did not affect comparisons of $V_{\mathrm{m}}$ tuning estimates, as comparison of RS and FS cells with either similar or very different firing rates did not change the results of the analyses. Spike output in response to drifting gratings was measured as the F1 and the DC of the mean firing rate for simple and complex cells, respectively. The magnitude of the $V_{\mathrm{m}}$ fluctuations associated with spikes evoked by visual stimuli was measured as the SD of the mean $V_{\mathrm{m}}$ value $\left(V_{\mathrm{m}} \mathrm{SD}\right)$ during the $10 \mathrm{~ms}$ preceding the threshold crossing of each spike. To normalize measurements across cells, all $V_{\mathrm{m}} \mathrm{SD}$ measurements were taken as the increase relative to the $V_{\mathrm{m}} \mathrm{SD}$ in the absence of visual stimulation. The $V_{\mathrm{m}} \mathrm{SD}$ was only measured when the interspike interval $\geq 10 \mathrm{~ms}$. This method of measurement avoided contamination of the $V_{\mathrm{m}} \mathrm{SD}$ values with artifacts left by spike removal and focused on the $V_{\mathrm{m}}$ fluctuations most closely associated with visually evoked spike output. To compare $V_{\mathrm{m}}$ fluctuations at optimal and nonoptimal orientations, the visually evoked increase in prespike $V_{\mathrm{m}} \mathrm{SD}$ was measured using drifting gratings at two orientations: one eliciting a maximal response and one eliciting a halfmaximal response.

Overall mean rate of $V_{\mathrm{m}}$ change $(\mathrm{d} V / \mathrm{d} t)$ was quantified by calculating the mean of the absolute value of the first derivative of a 10 to $30 \mathrm{~s}$ recording after spike removal $(|\mathrm{dV} / \mathrm{dt}|)$. Prespike $\mathrm{dV} / \mathrm{dt}$ was measured by calculating the $V_{\mathrm{m}}$ change over the $2 \mathrm{~ms}$ leading up to spike threshold. Prespike $\mathrm{dV} / \mathrm{dt}$ was measured only for spikes with an interspike interval of $\geq 10 \mathrm{~ms}$. For estimation of membrane time constant and input resistance in the absence of visual stimulation, we used a larger group of RS and FS cells that included those used in the rest of the study. Time constant and input resistance were measured from injection of 10-20 small square current pulses per cell.

Prediction of spike output. Two models were used to capture the relationship between membrane potential $\left(V_{\mathrm{m}}\right)$ and firing rate $(R)$ :

$$
\begin{gathered}
R\left(V_{m}\right)=k_{p}\left(V_{m}-V_{\text {rest }}\right)^{p} \\
R\left(V_{m}\right)=k_{1}\left(V_{m}-V_{\text {th }}\right)
\end{gathered}
$$

The power-law model (Eq. 1) is identical to that used previously (Miller and Troyer, 2002; Murphy and Miller, 2003; Priebe et al., 2004; Priebe and Ferster, 2006) (see also Carandini, 2004). Sets of values of $R$ and $V_{\mathrm{m}}$ were extracted from $20 \mathrm{~ms}$ bins in the responses to gratings drifting at all orientations and spatial frequencies. The scale factor $\left(k_{\mathrm{p}}\right)$ and the exponent $(p)$ were estimated from these sets of values using a nonlinear estimation procedure. The same sets of values were used to estimate the scale factor $\left(k_{1}\right)$ and threshold $\left(V_{\text {th }}\right)$ in the linear model (Eq. 2). 

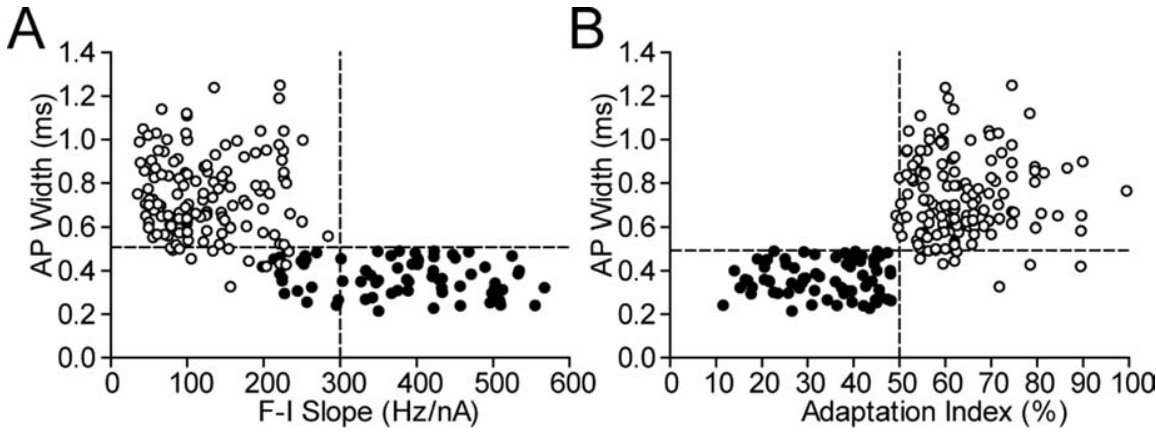

Figure 1. Classification of RS (open circles) and FS cells (filled circles). $\boldsymbol{A}$, Plot of $F$ - / slope against spike width, divided at an action potential width of $0.5 \mathrm{~ms}$, and an $\mathrm{F}-/$ slope of $300 \mathrm{~Hz} / \mathrm{nA}$. Although the two populations of cells are largely separated, there is some overlap evident in the lower left quadrant. $\boldsymbol{B}$, Plot of adaptation index (percentage of spikes occurring in the first $50 \mathrm{~ms}$ of a $100 \mathrm{~ms}$ current pulse) against action potential width. Here the two populations are clearly separated into two quadrants.

firing rate adaptation, and the slopes of their frequency-intensity $(F-I)$ relationships in response to square current pulses, as shown in Figure 1 (McCormick et al., 1985; Nowak et al., 2003). In addition, RS and FS cells differed in their spike afterhyperpolarization (AHP; FS cells have short and pronounced AHPs) (Fig. 2) and their overall firing rates in response to current injection ( $\mathrm{FS},>300 \mathrm{~Hz}$ ). Because the spontaneous activity of RS and FS cells varied widely across cells, the spontaneous firing rates of the two populations of cells were not significantly different.

\section{Orientation and spatial frequency tuning}

We measured orientation tuning with

Once the parameters were estimated for each cell, these equations were used to generate predicted orientation and spatial frequency tuning curves. Specifically, cyclegrams for stimuli presented at all orientations and spatial frequencies were binned at $20 \mathrm{~ms}$ and firing rates calculated from the $V_{\mathrm{m}}$ values according to Equations 1 and 2. The final result was the predicted F1 or DC components of the spike response as a function of orientation and spatial frequency.

Because, as we show below, the $V_{\mathrm{m}}$ SD varies systematically with stimulus parameters, we also used a variant of the linear model:

$$
R\left(V_{m}\right)=k_{1}\left[V_{m}+S N(\theta, f)-V_{\mathrm{th}}\right]^{+}
$$

where $V_{\text {th }}$ and $k_{1}$ are the same as in Eq. 2, but synaptic noise (SN) is added to the $V_{\mathrm{m}}$ obtained from each $20 \mathrm{~ms}$ bin. SN was drawn randomly from Gaussian distributions of zero mean whose SD matched that measured for each orientation and spatial frequency. A Gaussian distribution was used because the distribution of $V_{\mathrm{m}}$ values during baseline activity at resting $V_{\mathrm{m}}$ was well fit by a Gaussian in all cells. Because this model can occasionally produce small negative firing rates, the output was truncated at $0 \mathrm{~Hz}$ (rectified).

Statistical analysis. Statistics were used as described in Results. Unless otherwise noted, error bars denote SEM.

Histology. At the end of each experiment, the animal was given a lethal dose of sodium pentobarbital and perfused intracardially with $0.9 \%$ saline followed by cold 4\% paraformaldehyde in $0.1 \mathrm{~m}$ sodium phosphate buffer. The brain was post-fixed and cryoprotected, sectioned at $100 \mu \mathrm{m}$, and treated with Cy3-conjugated streptavidin (Jackson ImmunoResearch, West Grove, PA) to label cells filled with neurobiotin. To confirm recording locations and laminar positions, Cy3-labeled cells and laminar boundaries were visualized with an Olympus (Melville, NY) BX51 microscope. Examples of filled cells are shown in supplemental Figure 1 (available at www.jneurosci.org as supplemental material).

\section{Results}

The purpose of this study was to compare the orientation and spatial frequency selectivity of regular spiking and fast spiking neurons in primary visual cortex in vivo. Our initial database of cells included 671 neurons distributed throughout layers 2-6 of cat primary visual cortex (layers $2 / 3, n=175$; layer $4, n=168$; layers $5 / 6, n=328$ ). All cells included in the database had a stable resting $V_{\mathrm{m}}$ more negative than $-60 \mathrm{mV}$ for $>15 \mathrm{~min}$ and an overshooting action potential. Of those, 463 were RS cells and 73 were FS cells. We chose a subset of RS cells at random for statistical comparison with the smaller FS cell population ( $n=140$ RS and 73 FS) (supplemental Table 1, available at www.jneurosci.org as supplemental material, for details). Within these groups, 63 cells (35 RS, 28 FS) were located in layer 4. Cells were classified electrophysiologically according to their spike duration at half height (RS, $0.73 \pm 0.1 \mathrm{~ms}$; FS, $0.36 \pm 0.1 \mathrm{~ms}$ ), their degree of drifting gratings of optimal spatial frequency and quantified the responses by measuring the $\mathrm{F} 1$ and $\mathrm{DC}$ response components for simple and complex cells, respectively (see Materials and Methods). The orientation tuning curves for the $V_{\mathrm{m}}$ and spike responses of four representative cells are shown in Figure 2. A simple RS cell from layer 4 showed a characteristic, robustly modulated $V_{\mathrm{m}}$ response to optimally oriented drifting gratings with a peak to peak amplitude of $14.9 \mathrm{mV}$ and generated a modulated spike response with firing rates around $9.8 \mathrm{~Hz}$ (Fig. 2A). The half-maximal response elicited by a nonoptimally oriented grating is shown for comparison. The DC responses of this cell were similarly tuned (data not shown), although of much smaller amplitude. A complex RS cell from layer 5 (Fig. 2B) demonstrated a sustained (DC) response of $9.5 \mathrm{mV}$ to an optimally oriented drifting grating, leading to an unmodulated firing rate increase of $24.6 \mathrm{~Hz}$, and showed tuning of both the $V_{\mathrm{m}}$ and spike responses. A simple FS cell in layer 4 showed broader spike tuning than the simple layer $4 \mathrm{RS}$ cell, and less sharpening of the tuning of spike responses relative to $V_{\mathrm{m}}$ responses. In response to an optimally oriented grating, this cell showed peak to peak $V_{\mathrm{m}}$ fluctuations of $11.2 \mathrm{mV}$ (Fig. 2C) and firing rates of $56.8 \mathrm{~Hz}$. A complex FS cell in layer 5 had a $V_{\mathrm{m}}$ response to an optimally oriented grating of $10.1 \mathrm{mV}$ and it showed a sustained firing rate of $78.1 \mathrm{~Hz}$ (Fig. 2D). Additional example cells are shown in supplemental Figure 2 (available at www.jneurosci.org as supplemental material). Spatial frequency tuning was assessed with drifting gratings of optimal orientation and the responses were quantified as the F1 or DC components for simple and complex cells, respectively. Figure 3 shows the $V_{\mathrm{m}}$ and spike spatial frequency tuning curves for the four cells shown in Figure 2. The two simple cells shown in Figures 2 and 3 illustrate differences between layer 4 RS and FS cells that were consistent throughout the population. Layer 4 FS cells exhibited similar $V_{\mathrm{m}}$ tuning, but broader spike response tuning than layer $4 \mathrm{RS}$ cells. This difference was not observed in nongranular layers.

In agreement with previous reports (Ferster et al., 1996; Chung and Ferster, 1998; Anderson et al., 2000a), orientation tuning of spike responses was narrower than that of the underlying $V_{\mathrm{m}}$ responses. This is shown by the plot of $V_{\mathrm{m}} \mathrm{HWHH}$ versus spike HWHH in Figure $4 A$, in which most RS $(n=108)$ and FS $(n=61)$ cells fall below the unity line. Similarly, spatial frequency tuning of $V_{\mathrm{m}}$ responses was broader than that of spike responses for both RS $(n=76)$ and FS $(n=39)$ cells (Fig. $4 B)$. As shown by the accompanying histograms of $V_{\mathrm{m}}$ and spike tuning widths, when cells in all layers were included there were no significant differences between RS and FS population means for either ori- 
entation or spatial frequency (unpaired $t$ test; $p>0.05$ in all cases).

\section{Differences in stimulus selectivity between RS and FS cells in layer 4} When the comparison was limited to cells in layer 4, the orientation tuning of the spike response was significantly broader in FS than RS cells (RS, $14.5 \pm 1.0^{\circ}, n=31$; FS, $24.8 \pm 1.8^{\circ}, n=26$; Mann-Whitney test, $p<0.001$ ) (Fig. 4C). Spatial frequency tuning was also broader for the spike response of layer $4 \mathrm{FS}$ cells than layer 4 RS cells [FS, $2.30 \pm 0.27$ octaves (oct), $n=16$; RS, $1.31 \pm 0.16$ oct, $n=21 ; p<$ 0.01] (Fig. 4D). Surprisingly, the underlying $V_{\mathrm{m}}$ responses were not significantly different for either orientation (RS, $29.9 \pm$ $1.8^{\circ}$; FS, $32.8 \pm 2.4^{\circ} ; p>0.05$ ) (Fig. $4 C$ ) or spatial frequency (RS, $2.61 \pm 0.22$ oct; FS, $2.87 \pm 0.40 \mathrm{oct}$ ) (Fig. $4 D$ ). The $V_{\mathrm{m}}$ data suggest that the tuning of the summed synaptic input to layer 4 RS and FS cells is not significantly different for orientation or spatial frequency. However, cell typespecific intrinsic properties may differentially affect the conversion of synaptic input to spike output in layer 4 RS and FS cells.

\section{Differences in stimulus selectivity between RS and FS cells in nongranular layers and comparison with layer 4} The spike output tuning differences between layer 4 FS and RS cells were not replicated in downstream cortical layers. No significant differences between FS and RS orientation tuning for either $V_{\mathrm{m}}$ or spike responses were observed in supragranular ( $n=25 \mathrm{RS}$ and $11 \mathrm{FS}$ ) or infragranular ( $n=54 \mathrm{RS}$ and $25 \mathrm{FS}$ ) layers $(p>0.05$ in all cases) (supplemental Table 1, available at www.jneurosci.org as supplemental material). Similarly, no significant differences were observed between FS and RS spatial frequency tuning for the $V_{\mathrm{m}}$ or spike responses in supragranular ( $n=25 \mathrm{RS}$ and 4 FS) or infragranular ( $n=52 \mathrm{RS}$ and $18 \mathrm{FS})$ layers ( $p>0.05$ in all cases) (supplemental Table 1, available at www.jneurosci.org as supplemental material).

The lack of differences between RS and FS cells in nongranular layers, and particularly in layers $2 / 3$, could be attributable to their common excitatory input from layer 4 RS cells and differences in local connectivity. However, the orientation tuning of the spike output of layer 4 RS cells $\left(14.5 \pm 1.0^{\circ} ; n=28\right)$ was significantly narrower than both the $V_{\mathrm{m}}$ and spike tuning of their target RS $\left(V_{\mathrm{m}}, 47.5 \pm 4.5^{\circ}, p<0.001\right.$; spikes, $23.6 \pm 2.1^{\circ}, p=0.04$; oneway ANOVA with Dunn's multiple comparison test $)$ and FS ( $V_{\mathrm{m}}$, $42.6 \pm 8.9^{\circ}, p<0.001$; spikes, $\left.20.3 \pm 2.1^{\circ}, p=0.04\right)$ cells in supragranular layers. This significant decrease in selectivity suggests some degree of pooling of the sharply tuned output of layer
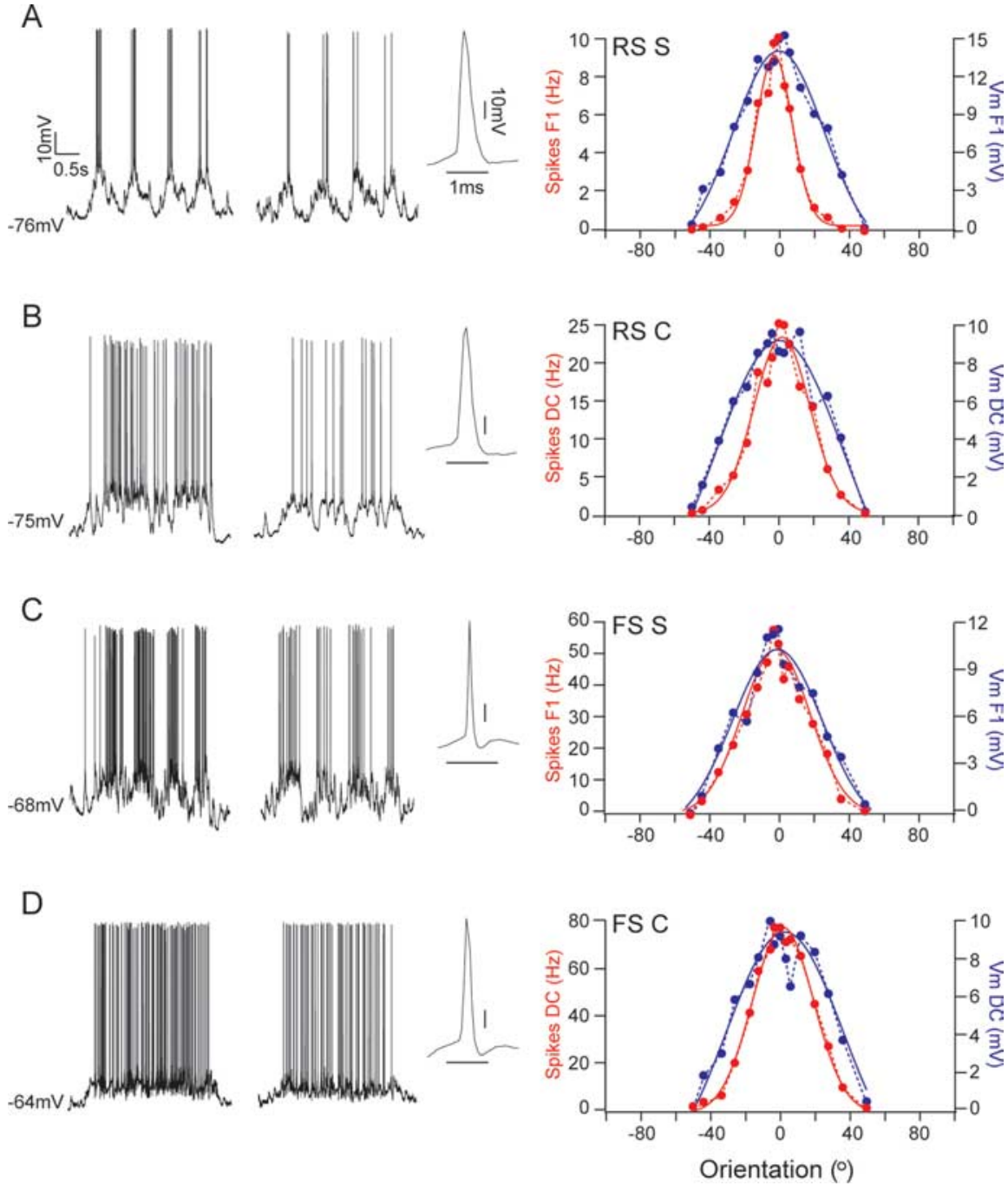

Figure 2. Orientation tuning curves of four representative neurons. In each case, one response to an optimally oriented stimulus (left trace) and one response to a stimulus at the half-width of the tuning curve (right trace) are shown on the left. $\boldsymbol{A}, \mathrm{A}$ simple RS cell in layer 4 showed a characteristic modulated $V_{m}$ and spike response to an optimal drifting grating (left trace). Spike duration at half height was $0.49 \mathrm{~ms}$ (left, inset spike). The $V_{\mathrm{m}}$ (blue) and spike (red) tuning curves of the F1 component of the visually evoked response show tuning for orientation (HWHH: $V_{m}, 29.7^{\circ}$; spikes, $13.1^{\circ}$ ). The tuning of the spike response was markedly narrower than that of the $V_{m}$ response. $B, A$ complex $R S$ cell in layer 5 showed an unmodulated, sustained response to an optimal drifting grating. Spike duration was $0.50 \mathrm{~ms}$. The $V_{\mathrm{m}}$ and spike tuning curves of the $D C$ component of the visual response were both well tuned for orientation (HWHH: $V_{m}, 32.6^{\circ}$; spikes, $19.9^{\circ}$ ). C, A representative simple FS cell in layer 4 showed modulated firing in response to an optimal grating. Spikes were characteristically short in duration ( $0.26 \mathrm{~ms})$ and showed a large, brief AHP. The $V_{m}$ of the cell showed tuning similar to that of the simple RS cells shown in $\boldsymbol{A}$, but the spike response of this cell was broader than that of the RS cell (HWHH: $V_{m}, 29.6^{\circ}$; spikes $\left.24.0^{\circ}\right)$. D, A complex FS cell in layer 5 showed a sustained level of fast spiking in response to an optimal grating and $V_{\mathrm{m}}$ and spike responses that were well tuned for orientation (HWHH: $V_{\mathrm{m}^{\prime}}$ $31.7^{\circ}$; spikes, $20.1^{\circ}$ ). The spike duration was $0.30 \mathrm{~ms}$.

4 cells, either directly at their synaptic targets in layers $2 / 3$ or indirectly via entrainment of extensive local recurrent excitation.

Across our population of recorded cells in all layers, we observed no RS or FS cells that were untuned for stimulus orientation or spatial frequency. In particular, none of the complex layer 4 FS cells we recorded were untuned $\left(n=6\right.$; orientation: $V_{\mathrm{m}}$, $30.1 \pm 8.3^{\circ}$; spikes, $26.8 \pm 10.8^{\circ}$; spatial frequency: $V_{\mathrm{m}}, 2.58 \pm$ 0.28 oct; spikes, $2.22 \pm 0.42 \mathrm{oct}$ ). We observed very few cells ( $n=$ 1 of 116 RS, 2 of 67 FS) with extremely broad $V_{\mathrm{m}}$ tuning for orientation ( $\mathrm{HWHH}>100^{\circ}$ ), and only one of those, a simple FS cell in layer 4, maintained such broad tuning in its spike output. We observed a number of cells that demonstrated low-pass spatial frequency tuning for $V_{\mathrm{m}}$ (12 of 108 RS cells; 11 of 41 FS cells) 

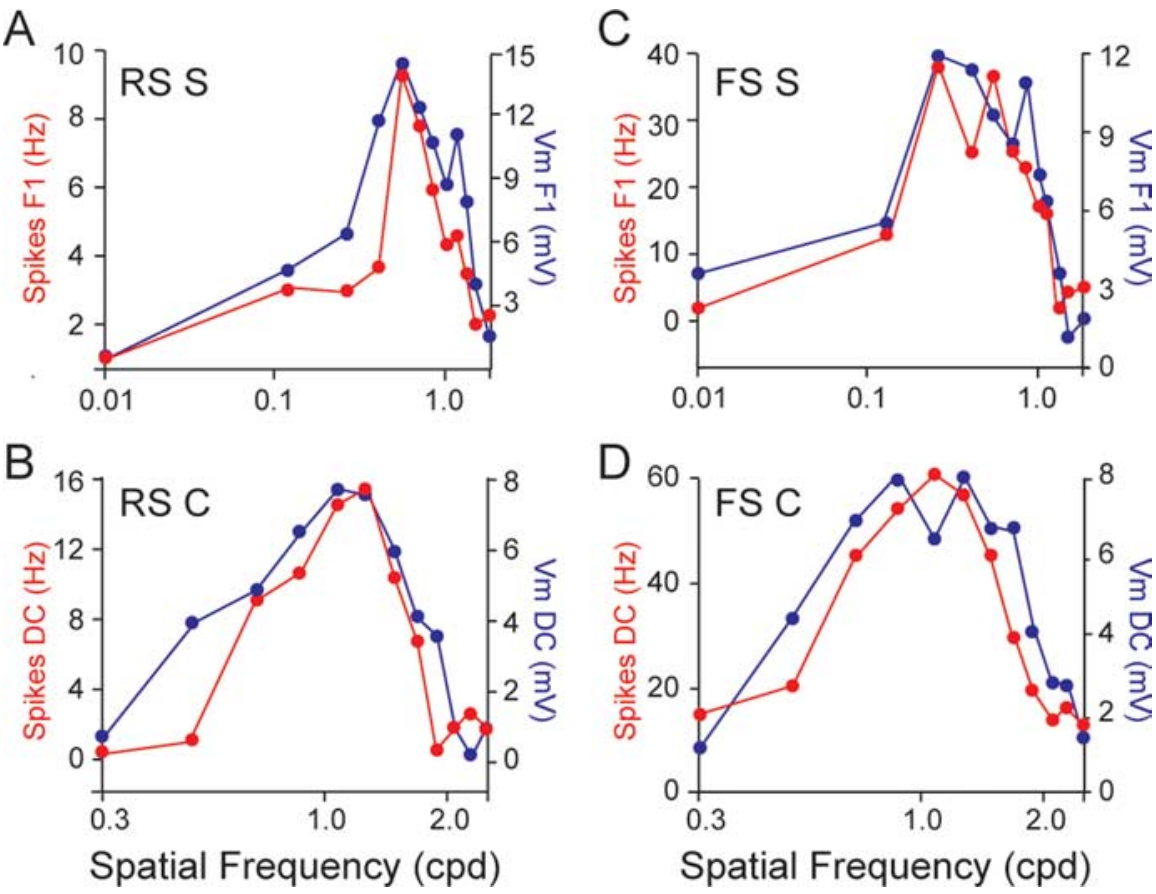

Figure 3. Spatial frequency tuning curves of the cells shown in Figure 1. $\boldsymbol{A}$, The layer 4 simple RS cell was well tuned for spatial frequency at both the $V_{m}$ (blue) and spike (red) levels (BW: $V_{m}, 2.80$ oct; spikes, 1.62 oct). $B$, Similarly, the $V_{m}$ and spike responses of the layer 5 complex RS cell were well tuned (BW: $V_{m}, 2.20$ oct; spikes, $1.450 \mathrm{ct}$ ). $C$, The $V_{m}$ response of the simple layer $4 \mathrm{FS}$ cell was similar to that of the layer $4 \mathrm{RS}$ cell shown in $\boldsymbol{A}$, but the spike response of the $\mathrm{FS}$ cell was more broadly tuned than that of the RS cell (BW: $V_{\mathrm{m}^{\prime}} 2.73$ oct; spikes, 2.32 oct). $D$, Tuning curves for the $V_{\mathrm{m}}$ and spike responses of the layer 5 complex FS cell (BW: $V_{\mathrm{m}}$ 2.24 oct; spikes, 1.62 oct).

and spikes (4 of 108 RS cells; 2 of 41 FS cells). Interestingly, in layer 4, although 0 of 23 RS cells demonstrated low-pass spatial frequency tuning for $V_{\mathrm{m}}, 5$ of $15 \mathrm{FS}$ cells did. No differences were observed in tuning for stimulus orientation or spatial frequency between simple and complex cells at the $V_{\mathrm{m}}$ or spike level $(n=87$ simple, 125 complex; $p>0.05$ in all cases) (data not shown). The average population values for orientation tuning and spatial frequency tuning in all cortical layers are shown in supplemental Table 1 (available at www.jneurosci.org as supplemental material).

\section{$V_{\mathrm{m}}$ responses predict spike tuning in $\mathrm{RS}$, but not $\mathrm{FS}$, cells in layer 4}

The broader orientation and spatial frequency tuning of the spike, but not $V_{\mathrm{m}}$, responses of layer $4 \mathrm{FS}$ may derive from differences in the transformation of $V_{\mathrm{m}}$ activity into spike output. To test this possibility, we generated a predicted spike output from the $V_{\mathrm{m}}$ responses of each layer 4 cell and compared the orientation and spatial frequency tuning curves of the predicted spike responses with those obtained experimentally. Predicted spike responses were generated by first obtaining power law fits for the relationship between $V_{\mathrm{m}}$ and firing rate for each cell. The power law fit parameters were then applied to each cell's averaged $V_{\mathrm{m}}$ responses to drifting grating stimuli to give predicted firing rates for each orientation or spatial frequency (see Materials and Methods).

The mean exponent of the power law functions for layer 4 FS cells $(2.5 \pm 0.05 ; n=24)$ was significantly higher than that for layer 4 RS cells $(1.8 \pm 0.08 ; n=25 ; p<0.001)$. A higher exponent should result in narrower FS spike response tuning, the opposite of the experimental observations described above. We thus expected that the power law predictions for FS cell spike tuning would underestimate the observed values. Indeed, as shown by the example cells in Figure 5, whereas the prediction was accurate for both the orientation and spatial frequency tuning of the layer 4 RS cell (Fig. $5 \mathrm{~A}, \mathrm{C}$, top plots), in both cases it underestimated the observed values for the layer 4 FS cell (Fig. $5 A, C$, bottom plots). Across the population of cells, this was true for both orientation (Fig. 5B) and spatial frequency (Fig. 5D). In both cases, data from RS cells fell close to the unity line, indicating a good match between predicted and observed values, whereas data from the FS cells fell predominantly below the line, indicating broader observed than predicted tuning. The mean ratio of predicted to observed HWHH of orientation tuning was significantly $<1$ for FS cells $(0.69 \pm 0.04 ; p<0.001$, one-sample $t$ test), indicating a poor match between predicted and observed tuning, but was close to 1 for RS cells $(1.04 \pm 0.03 ; p>$ $0.05)$. Similarly, the mean ratio of predicted to observed BW of spatial frequency was significantly $<1$ for FS cells $(0.71 \pm$ $0.05 ; p<0.001)$, but was close to 1 for RS cells $(1.06 \pm 0.02 ; p>0.05)$. Together, these results suggest that the broader tuning of FS cells is not a simple consequence of a static relationship between $V_{\mathrm{m}}$ and firing rate.

\section{$V_{m}$ fluctuations and spike tuning in layer 4 cells}

One possible mechanism underlying both the different stimulus selectivity of RS and FS spike responses and the failure of $V_{\mathrm{m}}$ values to predict spike response tuning in FS cells is cell type-specific differences in $V_{\mathrm{m}}$ fluctuations (also called synaptic noise). Increased synaptically driven $V_{\mathrm{m}}$ fluctuations, quantified as an increase in $V_{\mathrm{m}} \mathrm{SD}$ (see Materials and Methods), are likely to cause the $V_{\mathrm{m}}$ to cross the spike threshold more often, despite a similar level of mean $V_{\mathrm{m}}$ depolarization (Anderson et al., 2000b; Azouz and Gray, 2000). This impact of $V_{\mathrm{m}}$ fluctuations on spike output could lead to broader spike response tuning than that predicted from the $V_{\mathrm{m}}$ values, as was the case for layer 4 FS cells.

Indeed, the increase in $V_{\mathrm{m}} \mathrm{SD}$ evoked by visual stimuli was higher in layer 4 FS than RS cells not only in response to the preferred orientation (FS, $3.2 \pm 0.2 \mathrm{mV}, n=26$; RS, $1.9 \pm 0.1$ $\mathrm{mV}, n=31 ; p=0.03)$, but also to nonoptimally oriented stimuli that generated a half-maximal response (FS, $1.7 \pm 0.2$ $\mathrm{mV}, n=25$; RS, $0.8 \pm 0.1 \mathrm{mV}, n=32 ; p<0.001)$. These differences were not observed in nongranular cells for either the optimal (FS, $1.8 \pm 0.6 \mathrm{mV}, n=39$; RS, $2.0 \pm 0.5 \mathrm{mV}, n=$ $83 ; p>0.05$ ) or the nonoptimal (FS, $1.1 \pm 0.1 \mathrm{mV}, n=39$; RS, $1.0 \pm 0.1 \mathrm{mV}, n=83 ; p>0.05)$ orientation. Across the population of cells, the mean baseline $V_{\mathrm{m}} \mathrm{SD}$ in the absence of visual stimulation was $\pm 2.3 \mathrm{mV}$.

As shown by the example traces and tuning curves from the layer 4 RS and FS cells in Figure $6 A$, the magnitude of the visually evoked synaptic noise $\left(V_{\mathrm{m}} \mathrm{SD}\right)$ was tuned for stimulus orientation. In both example cells, the $V_{\mathrm{m}} \mathrm{SD}$ tuning curve agreed well with the tuning curve of the spike response. Indeed, for the pop- 
ulations of layer 4 RS and FS cells, the widths of the tuning curves for orientation (Fig. 6B) and spatial frequency (Fig. 6E) of the $V_{\mathrm{m}}$ SD response plotted against those of the spike responses were closer to the unity line than were the plots of $V_{\mathrm{m}}$ response versus spike response. $V_{\mathrm{m}}$ response tuning was consistently broader than $V_{\mathrm{m}}$ SD tuning in RS and FS cells for both orientation and spatial frequency (Fig. 6C,F). These results are highlighted by $\mathrm{HWHH}$ (Fig. 6D) and BW (Fig. 6G) ratios. In each case, the ratio of $V_{\mathrm{m}} \mathrm{SD}$ to spike tuning widths was close to 1 , indicating a close match between the $V_{\mathrm{m}} \mathrm{SD}$ and spike tuning curves. These results suggest that $V_{\mathrm{m}}$ fluctuations, rather than the overall level of $V_{\mathrm{m}}$ depolarization, may be a critical determinant in driving spike output in layer 4 cells.

\section{A linear model with tuned $V_{\mathrm{m}} \mathrm{SD}$ accurately predicts spike output in all layer 4 cells}

Because the $V_{\mathrm{m}}$ SD response was well tuned for both orientation and spatial frequency, we tested the hypothesis that a linear model of spike generation, in combination with tuned $V_{\mathrm{m}}$ noise, is a better predictor of spike output tuning properties than the power law model. For each cell, we compared the accuracy of the tuning predictions generated by a linear threshold (LT) model alone with the accuracy of predictions generated by adding $V_{\mathrm{m}}$ noise matched to the experimentally observed $V_{\mathrm{m}} \mathrm{SD}$ evoked by each stimulus condition. The observed $V_{\mathrm{m}} \mathrm{SD}$ response was measured in short epochs (see Materials and Methods). For illustrative pur-

poses, Figure $7 A$ shows several long example traces of visually evoked $V_{\mathrm{m}}$ SD. As shown by the orientation (Fig. 7A) and spatial frequency (Fig. 7D) tuning curves for two example cells, the LT prediction was much narrower than the observed tuning in each case. However, the linear threshold model with tuned noise (LTN) resulted in consistently accurate predictions of spike response tuning for both the RS and FS cells.

Across the populations of layer 4 RS $(n=25)$ and FS $(n=24)$ cells, the widths of the LTN-predicted tuning curve widths for orientation (Fig. 7B) and spatial frequency (Fig. 7E) were a close match to the observed tuning widths. In contrast, the LTpredicted tuning curve width consistently underestimated the observed spike tuning widths. Mean ratios of predicted to observed tuning widths are shown for orientation and spatial frequency in Figure 7, $C$ and $F$, respectively. In each case, the ratio of the LT prediction to the observed tuning was significantly smaller than $1(p<0.001$ in each case). In contrast, the ratio of LTN prediction to observed tuning width was not significantly different from 1 ( $p>0.05$ in each case). Unlike the power-law model (Fig. 5), the LTN model consistently generated accurate predictions of layer 4 FS cell spike output. These results suggest that tuned synaptic noise, in combination with $V_{\mathrm{m}}$ depolarization, is a
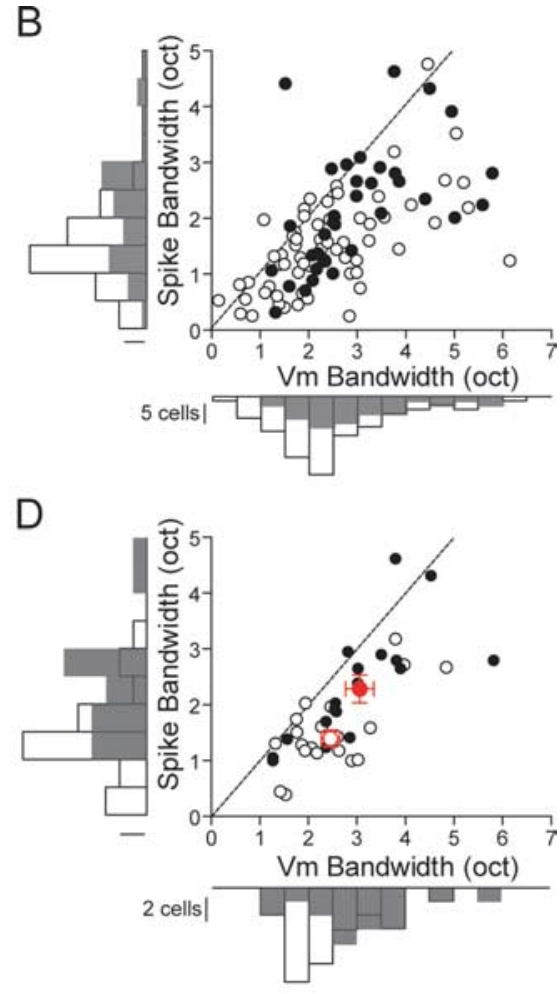

Figure 4. Population tuning characteristics for orientation and spatial frequency. $A$, Plot of $V_{m}$ versus spike orientation tuning a cells mostly fell below the unity line, indicating a sharpening of tuning in the transformation from $V_{\mathrm{m}}$ spike tuning when cells in all layers were included. C. Within layer 4 , there was no difference in $V$ orientation tuning between $(n=31)$ and FS ( $n=26)$ cells. However, as shown by the population means (red symbols) and accompanying histograms, FS cells showed significantly broader orientation tuning of spike responses. $\boldsymbol{D}$, There was no difference in $V_{\mathrm{m}}$ spatial frequency tuning between layer $4 \mathrm{RS}(n=21)$ and FS ( $n=16)$ cells. However, as highlighted by the population means and histograms, FS cells showed significantly broader spike tuning for spatial frequency.

key element in determining the stimulus selectivity of spike responses, especially in layer 4 FS cells.

\section{Role of membrane properties in stimulus selectivity}

We next explored whether the $V_{\mathrm{m}}$ fluctuation differences between layer 4 RS and FS cells are attributable to differences in visually evoked synaptic inputs or to differences in the biophysical properties of the postsynaptic cell. For instance, a shorter time constant would lead to shorter temporal summation, higher rates of membrane potential change $(\mathrm{d} V / \mathrm{d} t)$, and higher levels of $V_{\mathrm{m}}$ fluctuations in response to similar amounts of synaptic input. We therefore measured the mean $\mathrm{d} V / \mathrm{d} t$ during stimulation with optimal drifting gratings (see Materials and Methods). Examples from an RS and an FS cell in layer 4 are shown in Figure $8 \mathrm{~A}$. In response to a drifting grating stimulus of optimal parameters, the RS cell exhibited large $V_{\mathrm{m}}$ fluctuations that were slow compared with the rapid, sharp fluctuations of the FS cell. Within layer 4, FS cells demonstrated a significantly higher mean $\mathrm{d} V / \mathrm{d} t(0.35 \pm$ $0.02 \mathrm{mV} / \mathrm{ms} ; n=25)$ than did RS cells $(0.20 \pm 0.01 \mathrm{mV} / \mathrm{ms} ; n=$ $36 ; p=0.01)$. This difference was not replicated in supragranular (RS, $0.29 \pm 0.01 \mathrm{mV} / \mathrm{ms}$; FS, $0.28 \pm 0.02 \mathrm{mV} / \mathrm{ms}$ ) or infragranular (RS, $0.26 \pm 0.01 \mathrm{mV} / \mathrm{ms} ; \mathrm{FS}, 0.27 \pm 0.02 \mathrm{mV} / \mathrm{ms}$ ) layers. We also measured the $\mathrm{d} V / \mathrm{d} t$ of the membrane potential leading up to 
A
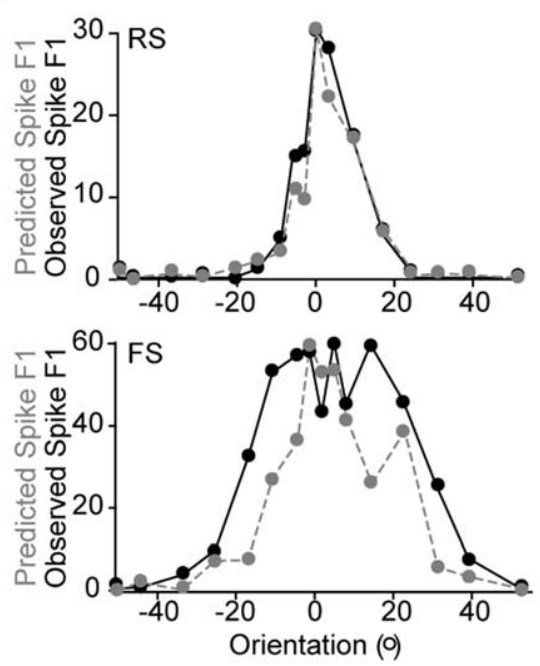

B

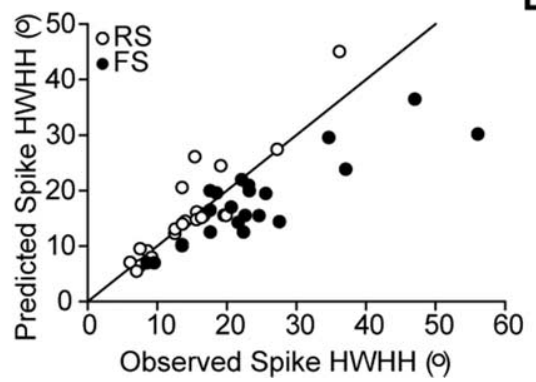

C
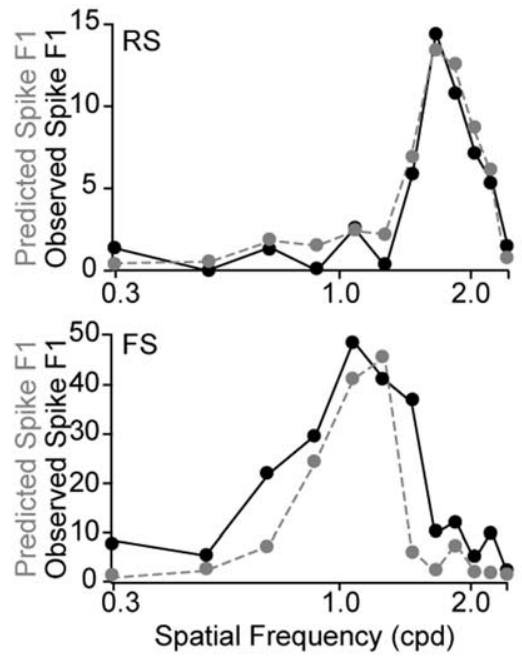

D

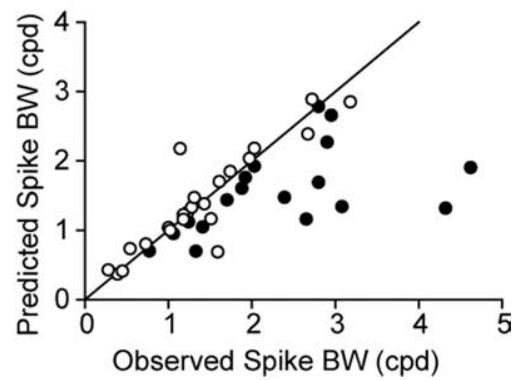

Figure 5. A power-law relationship between mean $V_{\mathrm{m}}$ depolarization and firing rate fails to predict the broad spike response tuning of layer $4 \mathrm{FS}$ cells. For each layer 4 cell, a set of power-law function parameters relating $V_{m}$ and firing rate were obtained from visually evoked activity. Those parameters were then used with averaged $V_{\mathrm{m}}$ activity to predict spike output during presentation of stimuli of varying orientations. $A$, For an example simple layer 4 RS cell (top), the predicted spike response tuning (gray) agreed well with the observed spike tuning (black). In contrast, the predicted spike tuning for an example simple layer $4 \mathrm{FS}$ cell (bottom) was narrower than the observed spike response tuning. $\boldsymbol{B}$, The RS cell values for observed versus predicted tuning (open circles) fell along the unity line, indicating close agreement. However, the values for FS cells (filled circles) predominantly fell below the line, indicating broader observed than predicted tuning. C, Predicted and observed spike tuning curves for spatial frequency for the two cells shown in $A$. As before, the prediction generated by power-law fits agreed well with the observed RS cell tuning, but underestimated the spatial frequency tuning bandwidth of the FS cell. D, Plot of predicted versus observed spatial frequency tuning. RS cell data fell mostly along the unity line, but FS cell data fell predominantly below the line.

spike threshold during visual stimulation. Within layer 4, FS cells demonstrated significantly faster prespike $\mathrm{d} V / \mathrm{d} t(4.0 \pm 0.1 \mathrm{mV} /$ $\mathrm{ms} ; n=25)$ than RS cells $(3.0 \pm 0.1 \mathrm{mV} / \mathrm{ms} ; n=36 ; p=0.003)$ (Fig. 8 B). This difference was not observed in supragranular (RS, $4.0 \pm 0.1 \mathrm{mV} / \mathrm{ms}$; FS, $3.9 \pm 0.2 \mathrm{mV} / \mathrm{ms}$ ) or infragranular (RS, $3.4 \pm 0.1 \mathrm{mV} / \mathrm{ms}$; FS, $3.7 \pm 0.2 \mathrm{mV} / \mathrm{ms}$ ) layers.

The faster $V_{\mathrm{m}}$ fluctuations observed in FS cells in response to synaptic input may be caused by biophysical membrane properties, such as the membrane time constant and input resistance, which play significant roles in determining the dynamics of synaptic integration (Eccles, 1964). We therefore measured these two variables for populations of RS and FS cells in all cortical layers (see Materials and Methods). FS cells in layer 4 demonstrated a significantly lower mean time constant $(4.2 \pm 0.6 \mathrm{~ms}$; $n=36)$ than did layer 4 RS cells $(6.1 \pm 0.5 \mathrm{~ms} ; n=69 ; p<0.001)$. This difference in membrane time constant was associated with a significantly lower input resistance in layer $4 \mathrm{FS}(27.3 \pm 9.8 \mathrm{M} \Omega)$ than RS $(47.1 \pm 11.4 \mathrm{M} \Omega ; p<0.001)$ cells. In addition, within layer 4 there was a linear, negative relationship between the membrane time constant and membrane $\mathrm{d} V / \mathrm{d} t$ during visual stimula- tion, suggesting that smaller time constants contribute to faster synaptically driven $V_{\mathrm{m}}$ fluctuations (RS, $n=20$; FS, $n=14 ; r^{2}=0.45 ; p<0.0001$ ) (data not shown). No differences in membrane time constant were observed between RS and FS cells in supragranular (RS, $n=102$; FS, $n=24$ ) or infragranular (RS, $n=159$; FS, $n=42$ ) layers $(p>0.05$ in all cases) (supplemental Table 1, available at www. jneurosci.org as supplemental material).

If biophysical membrane properties contribute to the emergence of stimulus selectivity in layer 4 cells, a relationship between the membrane time constant and the tuning of the cell's spike output is expected. Indeed, within layer 4 , membrane time constant values were linearly related to the width of the spike response orientation tuning curve (RS, $n=24$; FS, $n=20$; $\left.r^{2}=0.45 ; p<0.0001\right)$. Cells with smaller time constants demonstrated broader tuning for stimulus orientation.

Together, these results show that layer 4 FS cells exhibit faster membrane time constants than do layer 4 RS cells, and this property is associated with faster visually evoked $V_{\mathrm{m}}$ fluctuations. In turn, the $V_{\mathrm{m}}$ fluctuations determine spike output and result in significantly broader tuning of the spike output of layer 4 FS cells, despite the similar tuning of FS and RS cell mean $V_{\mathrm{m}}$ responses. In summary, our results demonstrate a difference in stimulus selectivity in layer 4 that derives from neuronal biophysical properties, rather than from the selectivity of synaptic inputs.

\section{Discussion}

Previous work has suggested that excitatory and inhibitory neurons may play distinct roles in shaping stimulus selectivity in visual cortex. However, their functional properties have not been systematically studied. Here, we compared the stimulus selectivity and membrane properties of excitatory and inhibitory neurons throughout primary visual cortex.

Within layer 4, RS and FS cells exhibited equal orientation and spatial frequency tuning of their $V_{\mathrm{m}}$ responses, but FS cells showed significantly broader spike output tuning. A power law model of the relationship between $V_{\mathrm{m}}$ activity and spike output accurately predicted layer 4 RS cell spike tuning, but consistently underestimated the tuning of FS cells. Because the tuning of synaptic noise $\left(V_{\mathrm{m}} \mathrm{SD}\right)$ agreed well with that of the spike output, especially in FS cells, we hypothesized that synaptic noise plays a significant role in determining spike response tuning. Indeed, a linear threshold model that incorporated tuned noise accurately predicted spike response tuning for the population of layer 4 FS cells.

We found that layer 4 FS cells have lower membrane time constants and input resistance and faster visually evoked $V_{\mathrm{m}}$ fluctuations than layer $4 \mathrm{RS}$ cells. Thus, the difference in the stimulus selectivity of layer 4 RS and FS spike responses is not driven by 
A
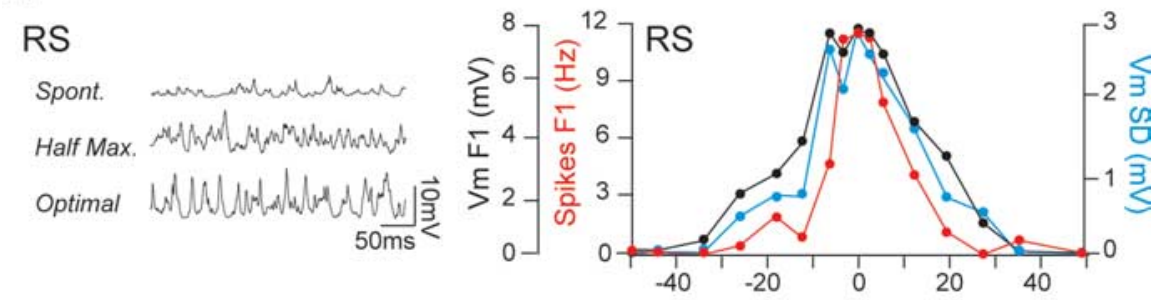

FS

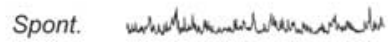

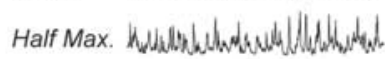

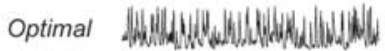

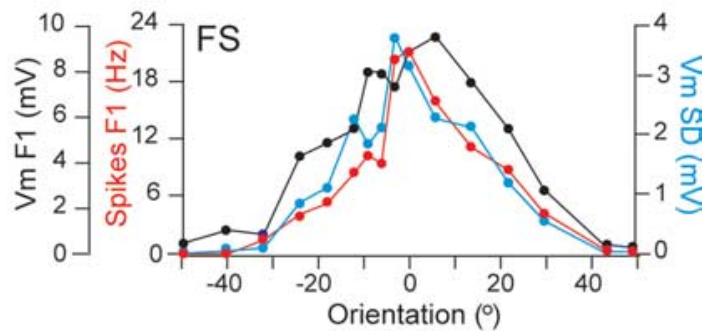

B
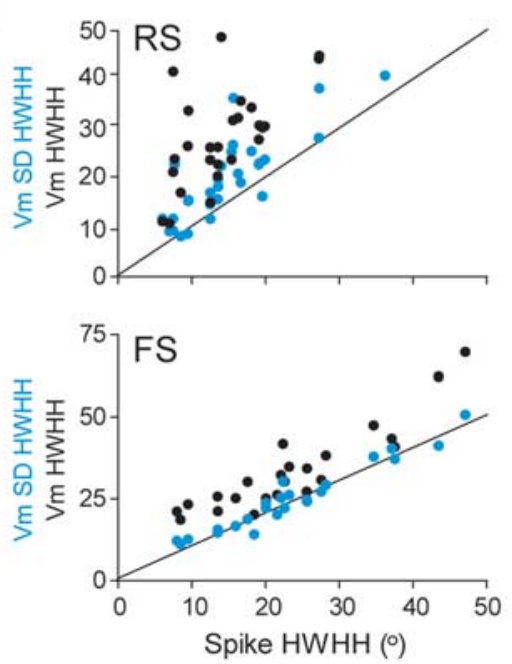

E
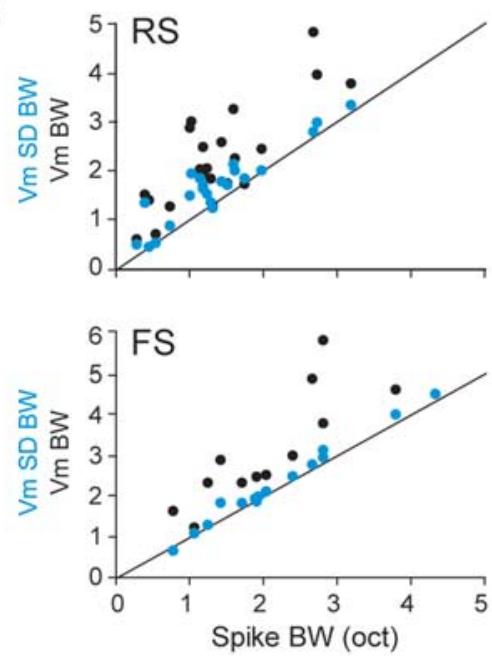

C

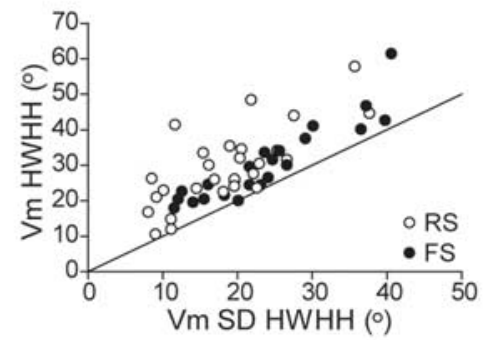

$\mathrm{F}$
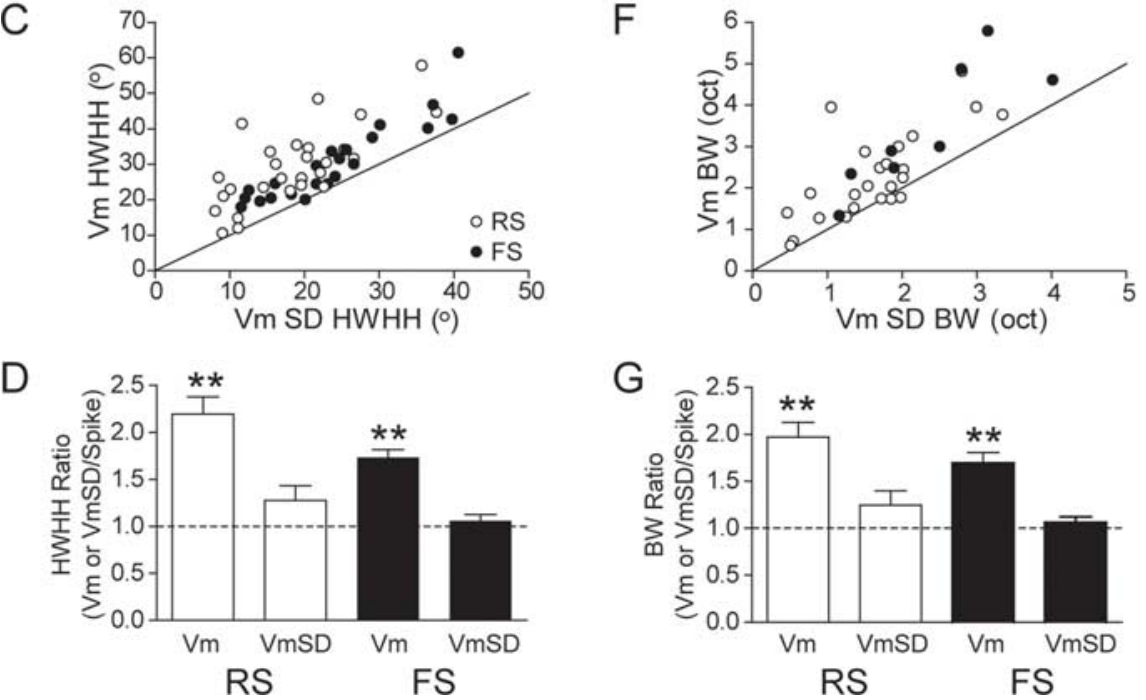

G

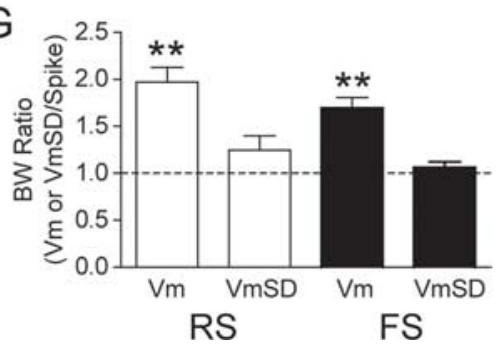

Figure 6. Tuning of $V_{\mathrm{m}}$ fluctuations matches spike response tuning in layer 4 cells. $A$, Synaptically driven $V_{\mathrm{m}}$ fluctuations were measured during presentation of stimuli of varying orientations. The $V_{m}$ response (black), spike response (red), and $V_{m}$ fluctuation response ( $V_{m} S D$; blue) tuning curves for a representative $R S$ (top) and FS (bottom) cell in layer 4 were well tuned for orientation. Example $V_{m}$ traces showing visually evoked $V_{m}$ fluctuations in each cell are shown to the left. Particularly in the FS cell, the $V_{m} S D$ tuning curve agreed well with the spike response tuning curve. $\boldsymbol{B}$, The HWHH of the spike response, $V_{\mathrm{m}}$ response, and $V_{\mathrm{m}} \mathrm{SD}$ response tuning curves were measured for each cell. Each cell's spike HWHH is plotted against the $V_{m} H W H H$ (black circles) and against the $V_{m} S D$. HWHH (blue circles). For both RS (top) and FS (bottom) cells, the values for the $V_{m} S D$ tuning width fell closer to the unity line than did the values for the $V_{m}$ tuning width. $C$, Plot of the HWHH of the $V_{m}$ SD response against that of the $V_{m}$ response. Both RS (open circles) and FS cells (filled circles) fall above the line. $D$, Bar graphs show the ratios of $V_{m}$ and $V_{m} S D$

differences in the tuning of their overall synaptic input, but rather by cell typespecific differences in biophysical membrane properties that mediate the dynamics of synaptically driven $V_{\mathrm{m}}$ fluctuations.

\section{Tuning of excitation and inhibition in} local cortical networks

Theoretical studies of orientation tuning in layer 4 have incorporated untuned or broadly tuned inhibition as an important component underlying either the emergence of selectivity or its contrast invariance (Somers et al., 1995; Troyer et al., 1998; Lauritzen and Miller, 2003; Ringach et al., 2003). In previous work, Hirsch et al. (2003) described four smooth stellate cells in layer 4 that were complex and demonstrated no selectivity for the orientation of moving bars. Similar results were found in layer $2 / 3$ of mouse visual cortex (Sohya et al., 2007). Such cells are obvious candidates to provide untuned inhibition to local cortical circuits. However, the orientation tuning of postsynaptic inhibitory potentials and conductances in layer 4 cells is narrow and indistinguishable from the tuning of postsynaptic excitatory potentials and conductances (Anderson et al., 2000a; Monier et al., 2003). In fact, this relatively narrow tuning of inhibitory synaptic inputs is suggested by the widely accepted push-pull receptive field structure of layer 4 simple cells (Hirsch, 2003; Hirsch and Martinez, 2006). Furthermore, neither elimination of all intracortical activity (Ferster et al., 1996; Chung and Ferster, 1998) nor specific postsynaptic blockage of GABAergic conductances (Nelson et al., 1994) affects orientation tuning. These results

orientation tuning width to spike response orientation tuning width. A value of 1 indicates a good match between tuning curves. For both RS (open bars) and FS (filled bars) cells, the ratio of $V_{m}$ to spike response tuning width was significantly $>1$ (RS, $2.20 \pm 0.18$; FS, $1.61 \pm 0.08)$. In contrast, the ratio of $V_{m}$ SD to spike response tuning was not significantly different from 1 for either population of cells (RS, $1.27 \pm 0.21 ; F S, 1.06 \pm 0.07)$. $\boldsymbol{E}$, The BW of each cell's spike response is plotted against the $V_{m} B W$ and the $V_{m} S D B W$. For both RS (top) and FS (bottom) cells, the $V_{m}$ SD values fell closer to the unity line than did the values for mean $V_{m} . F$, Plot of the BW of the $V_{m}$ SD response against that of the $V_{m}$ response. Again, both RS and FS cells fall mostly above the unity line. $G$, Ratios of $V_{m}$ and $V_{m} S D$ tuning BW to spike response tuning BW for RS and FS cells. Again, whereas the $V_{m}$ to spike response ratios were significantly $>1$ (RS, $1.86 \pm 0.16$; FS, $1.68 \pm 0.11)$, the $V_{m}$ SD to spike response ratios were not significantly different from 1 for either RS or FS cells (RS, $1.21 \pm 0.15 ; \mathrm{FS}, 1.05 \pm 0.04) .{ }^{* *} p<0.001$. Error bars indicate SEM. 
A
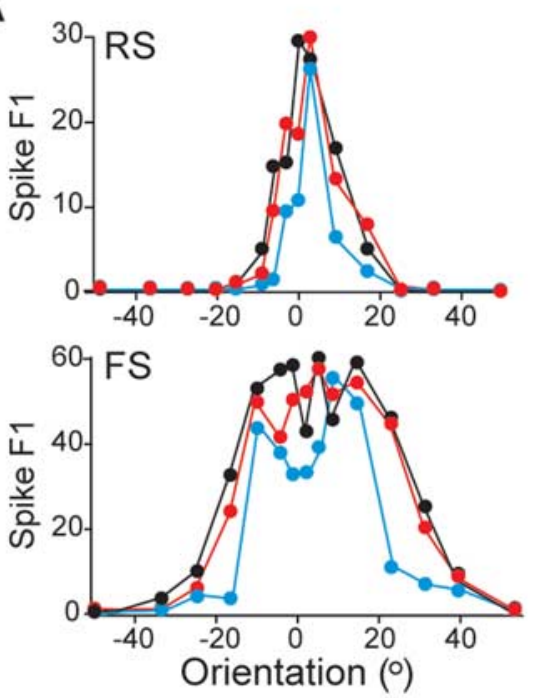

B
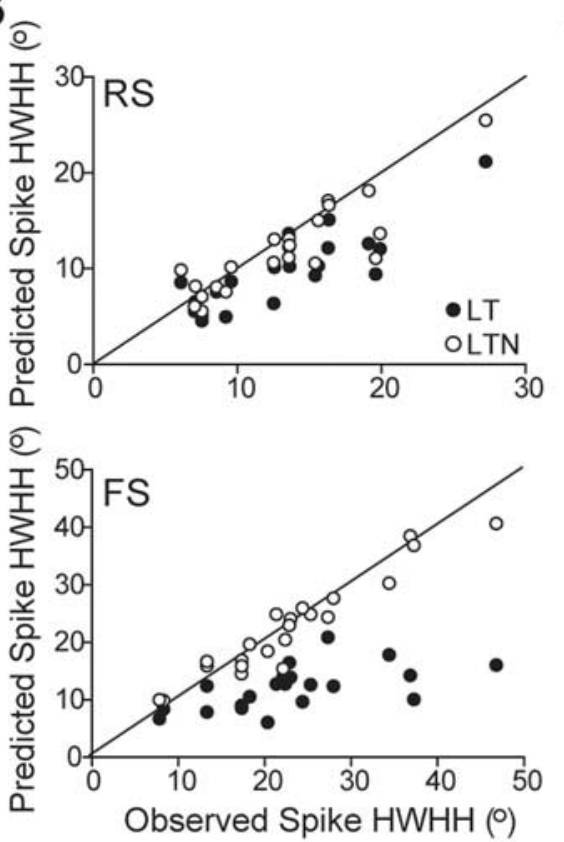

C

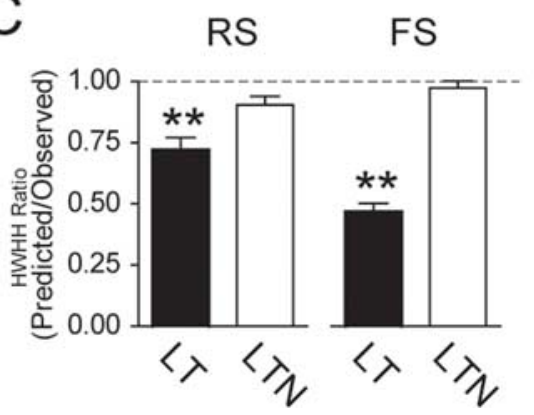

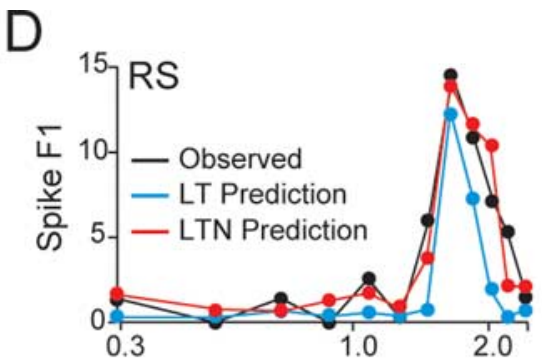
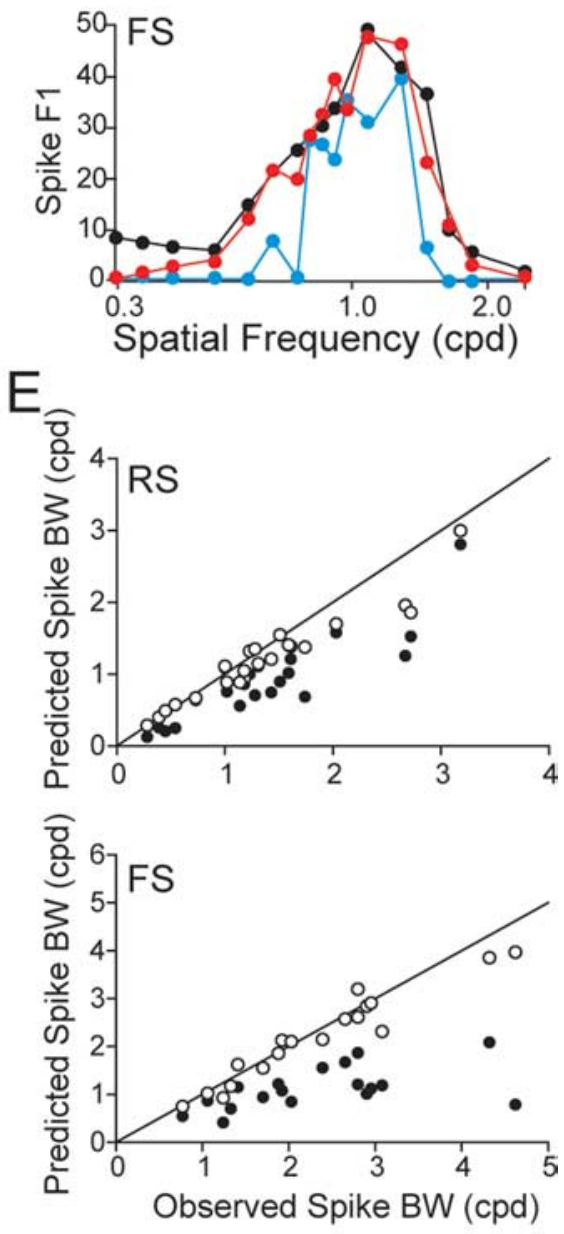

$\mathrm{F}$

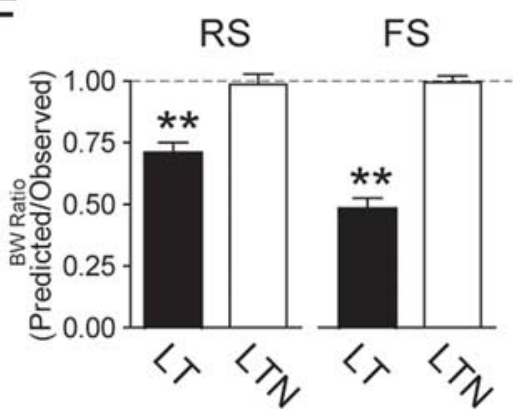

Figure 7. A linear threshold model with tuned noise accurately predicts the spike response tuning of layer 4 FS cells. Spike response tuning curve predictions were generated using the linear threshold model alone and in combination with tuned membrane potential noise. A, Predicted and observed orientation tuning curves for an example layer 4 RS (top) and FS (bottom) cell. In each case, the LT model prediction (blue) underestimated the width of observed spike response tuning curve (black), but the LTN model with added tuned noise (red) generated an accurate prediction of tuning curve width. B, For both RS (top) and FS (bottom) cells, the LTN tuning prediction fell closer to the unity line than did the LT prediction. C, Ratios of predicted to observed spike response tuning for orientation (HWHH). A value of 1 indicates good agreement with the observed spike response tuning curve. In each case, the LT prediction (filled bars) was significantly $<1$ (RS, $0.69 \pm 0.04$; $F S, 0.54 \pm 0.04$ ), whereas the LTN prediction (open bars) was not different from 1 ( $R S, 0.92 \pm 0.06 ; F S, 0.97 \pm 0.05$ ). $D$, Predicted and observed spatial frequency tuning curves

suggest that local inhibition, whether tuned or untuned, is not necessary for the expression of orientation selectivity in layer 4.

The data presented here represent the largest population of inhibitory neurons recorded to date in layer 4 . We observed no (0 of 21 simple; 0 of 7 complex) untuned layer 4 FS cells. Only one, a simple cell, exhibited spike response tuning broader than 100 degrees. Although we did observe that the orientation tuning of layer 4 FS cell spike output was systematically broader than that of layer 4 RS cells, this difference was relatively small $\left(10^{\circ}\right)$. It therefore seems unlikely that the broader tuning of FS cells plays more than a minor role in directly shaping the tuning curves of RS cells. At most, it may contribute a small sharpening that would likely fall below the resolution of the measurements made in previous studies of cortical inactivation (Nelson et al., 1994; Ferster et al., 1996; Chung and Ferster, 1998). It is difficult to reconcile our results with those of Hirsch et al. (2003). One possibility is that the disparity in observation of untuned FS cells may be attributable to the sampling biases inherent in different intracellular recording techniques. In addition, the small number of previously recorded untuned inhibitory cells (four cells) (Hirsch et al., 2003), in combination with observations that the inhibitory input to simple cells drops to low values at nonpreferred orientations (Ferster, 1986; Anderson et al., 2000a; Martinez et al., 2002), suggests that such cells may be rare. Another factor affecting comparisons between this and other work is the often sparse sampling of tuning curves $\left(22.5^{\circ}\right.$ steps $)$ by other studies, which may contribute to misestimation of tuning width.

We found no differences between RS and FS cells in either orientation or spatial frequency tuning outside of layer 4 . Furthermore, the tuning of layer 4 RS spike output was significantly narrower than both the $V_{\mathrm{m}}$ and spike responses of target supragranular RS and FS cells, suggesting

for the example cells shown in $A$. The LT prediction underestimated the actual spike response tuning, but the LTN prediction was a good match. $E$, Again, for both RS and FS cells, the LTN tuning prediction fell closer to the unity line than did the LT prediction. $\boldsymbol{F}$, Ratios of predicted to observed spike response tuning for spatial frequency (BW). In each case, the LT prediction was significantly $<1$ ( $\mathrm{RS}, 0.65 \pm 0.04 ; \mathrm{FS}, 0.54 \pm$ 0.03 ), whereas the LTN prediction was not different from 1 ( $R S, 0.91 \pm 0.02 ; F S, 0.96 \pm 0.03$ ), indicating a good match between the LTN prediction and the observed spike response tuning. ${ }^{* *} p<0.001$. Error bars indicate S.E.M. 

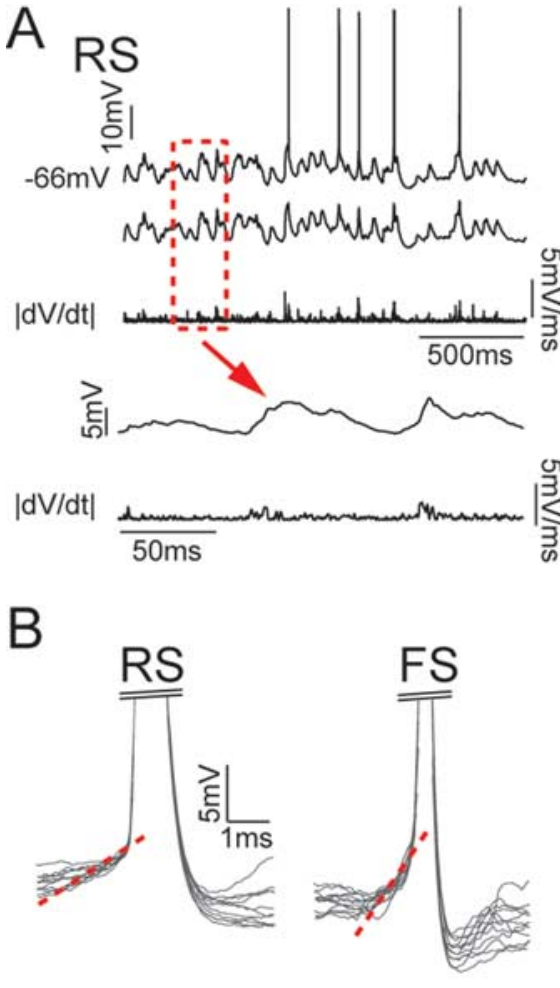
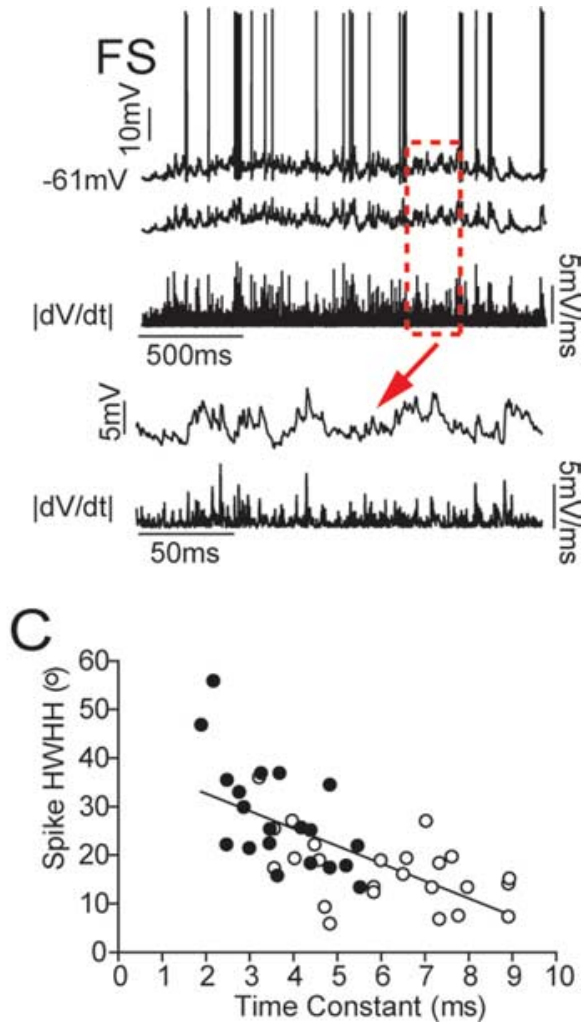

Figure 8. Synaptically evoked $V_{m}$ fluctuations are faster in $\mathrm{FS}$ than $\mathrm{RS}$ cells in layer 4. A, Comparison between the visually evoked $V_{m}$ fluctuations of an RS (left traces) and an FS (right traces) cell in layer 4. Portions denoted by the dashed red boxes are expanded below. Raw traces are shown on the top, followed by the same traces after spike removal. The third trace shows the rate of $V_{m}$ change $(\mid d V / d t)$ ), calculated as the absolute value of the first derivative of the recorded trace after spike removal. Note the sharp, fast $V_{\mathrm{m}}$ fluctuations in the $\mathrm{FS}$ cell recording, which result in a large mean $\mathrm{d} V / \mathrm{d} t$ magnitude. $\boldsymbol{B}$, Overlaid traces of individual spikes from the RS and FS cells shown in $A$. Spikes have been truncated. The mean $\mathrm{dV} / \mathrm{d} t$ in the 2 ms leading up to spike threshold, denoted by the dashed red lines, was faster in the FS than the RS cells. C, Biophysical membrane properties are correlated with stimulus feature selectivity in layer 4 neurons. Layer 4 RS cells are shown as open circles and layer $4 \mathrm{FS}$ cells are shown as filled circles. Membrane time constant values were linearly related to the HWHH of the spike orientation tuning of layer 4 cells. Cells with lower membrane time constants exhibited less selectivity for stimulus orientation than cells with higher time constants $\left(r^{2}=\right.$ $0.47 ; p<0.0001)$ ship between the average $V_{\mathrm{m}}$ and firing rate, in which the transition from subthreshold to suprathreshold activity is smoothed by $V_{\mathrm{m}}$ noise (Hansel and van Vreeswijk, 2002; Miller and Troyer, 2002; Murphy and Miller, 2003; Prescott and De Koninck, 2003; Carandini, 2004; Priebe et al., 2004). The power law fits for FS cells showed higher exponent values than those for RS cells, indicating cell type-specific differences in the slope of the relationship between $V_{\mathrm{m}}$ and firing rate similar to those observed from responses to injected current pulses both in vitro (Connors et al., 1982; Kawaguchi, 1993) and in vivo (Contreras and Palmer, 2003; Nowak et al., 2003). However, higher power law exponents should give rise to narrower, not broader, spike-orientation tuning. Indeed, tuning predictions generated from $V_{\mathrm{m}}$ activity and power-law fits agreed well with the actual spike output of RS cells, but consistently underestimated the width of FS cell spike response tuning. The power law model assumes a static relationship between $V_{\mathrm{m}}$ noise and spike output. However, membrane potential noise, measured as $V_{\mathrm{m}} \mathrm{SD}$, is tuned for visual stimulus parameters. The modified linear threshold model, which accounted for this nonlinear contribution by tuned noise, generated accurate predictions of spike response tuning in both RS and FS cells. Together, these results suggest that the broader tuning of FS cells does not derive from a simple relationship between the overall level of $V_{\mathrm{m}}$ depolarization and firing rate, but is instead greatly influenced by large, fast $V_{\mathrm{m}}$ fluctuations. downstream pooling of the narrowly tuned output of layer 4 cells or recruitment of the extensive recurrent local connections within supragranular layers. It is unlikely that differences in morphological characteristics alone can explain the difference between FS cells in layers 4 and 2/3. The main inhibitory cell type in cat layer 4 is a small basket cell that differs from supragranular basket cells only in size. The morphological differences among inhibitory cells in layer $2 / 3$ are far greater than those between those in layer $2 / 3$ and layer 4 , and yet their biophysical properties are homogeneous. Network input, which underlies the functional differentiation of simple and complex neurons, may likewise shape the distinct tuning properties of morphologically similar interneurons in different cortical layers.

\section{$V_{\mathrm{m}}$ fluctuations and visually evoked spike responses.}

One mechanism underlying the different spike response tuning of RS and FS cells in layer 4 may be differences in visually driven $V_{\mathrm{m}}$ fluctuations. Previous studies have suggested that $V_{\mathrm{m}}$ fluctuations lead to an increase in sensory-evoked spike responses by eliciting more frequent spike threshold crossings (Anderson et al., 2000b; Azouz and Gray, 2003) and lowering the spike threshold (Azouz and Gray, 2000; Wilent and Contreras, 2005a).

Several previous studies have suggested a power-law relation-
Intrinsic biophysical properties contribute to stimulus selectivity.

Passive electrical membrane properties, such as the membrane time constant, play a pivotal role in regulating synaptic integration (Rall, 1957; Coombs et al., 1959; Curtis and Eccles, 1960; Eccles, 1961). In particular, the rate of membrane potential change $(\mathrm{d} V / \mathrm{d} t)$, which is partly determined by the membrane time constant, influences the complex relationship between $V_{\mathrm{m}}$ depolarization and spike threshold (Azouz and Gray, 2000; Wilent and Contreras, 2005a). Layer 4 FS cells showed lower membrane time constants and input resistance than RS cells. Thus, the observed differences in RS and FS cell $V_{\mathrm{m}}$ fluctuations may be caused by cell type-specific differences in biophysical membrane properties (Spencer and Kandel, 1961; Brown et al., 1981; Connors et al., 1982). Indeed, recent in vitro findings in barrel cortex suggest that lower input resistance and fast time constants may be general properties of layer 4 interneurons (Cruikshank et al., 2007). Layer 4 FS cells receive stronger and more numerous thalamocortical synaptic inputs than layer 4 RS cells (Gibson et al., 1999; Porter et al., 2001; Bruno and Simons, 2002; Cruikshank et al., 2007). These differences offset the lower input resistance of FS cells, leading to synaptic responses of larger amplitude. The different transformation from $V_{\mathrm{m}}$ to spikes in RS and FS cells in layer 4 may 
be the combined effect of differences in intrinsic biophysical properties and synaptic dynamics. Stimulus selectivity in layer 4 cortical neurons, previously suggested to be predominantly determined by feedforward inputs (Miller, 2003), is thus partly the result of biophysical membrane properties.

In the somatosensory barrel system, suspected interneurons in layer 4 exhibit very broad directional tuning (Swadlow, 1995; Alonso and Swadlow, 2005). However, our data show that this is not the general case for stimulus selectivity in cat primary visual cortex interneurons. A high degree of selectivity, observed in cat and monkey visual cortex, but not in barrel cortex, may require sharply tuned inhibition for fine regulation of spike timing or spike output frequency, rather than overall damping of feedforward excitatory inputs. The results described here may serve to constrain conceptual models of visual cortex that require broadly tuned inhibition.

\section{References}

Alonso JM, Swadlow HA (2005) Thalamocortical specificity and the synthesis of sensory cortical receptive fields. J Neurophysiol 94:26-32.

Anderson JS, Carandini M, Ferster D (2000a) Orientation tuning of input conductance, excitation, and inhibition in cat primary visual cortex. J Neurophysiol 84:909-926.

Anderson JS, Lampl I, Gillespie DC, Ferster D (2000b) The contribution of noise to contrast invariance of orientation tuning in cat visual cortex. Science 290:1968-1972.

Azouz R, Gray CM (2000) Dynamic spike threshold reveals a mechanism for synaptic coincidence detection in cortical neurons in vivo. Proc Natl Acad Sci USA 97:8110-8115.

Azouz R, Gray CM (2003) Adaptive coincidence detection and dynamic gain control in visual cortical neurons in vivo. Neuron 37:513-523.

Azouz R, Gray CM, Nowak LG, McCormick DA (1997) Physiological properties of inhibitory interneurons in cat striate cortex. Cereb Cortex 7:534-545.

Brown TH, Fricke RA, Perkel DH (1981) Passive electrical constants in three classes of hippocampal neurons. J Neurophysiol 46:812-827.

Bruno RM, Simons DJ (2002) Feedforward mechanisms of excitatory and inhibitory cortical receptive fields. J Neurosci 22:10966-10975.

Carandini M (2004) Amplification of trial-to-trial response variability by neurons in visual cortex. PLoS Biol 2:E264.

Cardin JA, Palmer LA, Contreras D (2005) Stimulus-dependent gamma $(30-50 \mathrm{~Hz})$ oscillations in simple and complex fast rhythmic bursting cells in primary visual cortex. J Neurosci 25:5339-5350.

Chung S, Ferster D (1998) Strength and orientation tuning of the thalamic input to simple cells revealed by electrically evoked cortical suppression. Neuron 20:1177-1189.

Connors BW, Gutnick MJ, Prince DA (1982) Electrophysiological properties of neocortical neurons in vitro. J Neurophysiol 48:1302-1320.

Contreras D, Palmer L (2003) Response to contrast of electrophysiologically defined cell classes in primary visual cortex. J Neurosci 23:6936-6945.

Coombs JS, Curtis DR, Eccles JC (1959) The electrical constants of the motoneurone membrane. J Physiol (Lond) 145:505-528.

Cruikshank SJ, Lewis TJ, Connors BW (2007) Synaptic basis for intense thalamocortical activation of feedforward inhibitory cells in neocortex. Nat Neurosci.

Curtis DR, Eccles JC (1960) Synaptic action during and after repetitive stimulation. J Physiol (Lond) 150:374-398.

Eccles JC (1961) Membrane time constants of cat motoneurons and time courses of synaptic action. Exp Neurol 4:1-22.

Eccles JC (1964) The physiology of synapses. Berlin: Springer.

Ferster D (1986) Orientation selectivity of synaptic potentials in neurons of cat primary visual cortex. J Neurosci 6:1284-1301.

Ferster D (1987) Origin of orientation-selective EPSPs in simple cells of cat visual cortex. J Neurosci 7:1780-1791.

Ferster D (1988) Spatially opponent excitation and inhibition in simple cells of the cat visual cortex. J Neurosci 8:1172-1180.

Ferster D, Chung S, Wheat H (1996) Orientation selectivity of thalamic input to simple cells of cat visual cortex. Nature 380:249-252.

Gibson JR, Beierlein M, Connors BW (1999) Two networks of electrically coupled inhibitory neurons in neocortex. Nature 402:75-79.
Hansel D, van Vreeswijk C (2002) How noise contributes to contrast invariance of orientation tuning in cat visual cortex. J Neurosci 22:5118-5128.

Higley MJ, Contreras D (2006) Balanced excitation and inhibition determine spike timing during frequency adaptation. J Neurosci 26:448-457.

Hirsch JA (2003) Synaptic physiology and receptive field structure in the early visual pathway of the cat. Cereb Cortex 13:63-69.

Hirsch JA, Martinez LM (2006) Circuits that build visual cortical receptive fields. Trends Neurosci 29:30-39.

Hirsch JA, Martinez LM, Alonso JM, Desai K, Pillai C, Pierre C (2002) Synaptic physiology of the flow of information in the cat's visual cortex in vivo. J Physiol (Lond) 540:335-350.

Hirsch JA, Martinez LM, Pillai C, Alonso JM, Wang Q, Sommer FT (2003) Functionally distinct inhibitory neurons at the first stage of visual cortical processing. Nat Neurosci 6:1300-1308.

Jones JP, Stepnoski A, Palmer LA (1987) The two-dimensional spectral structure of simple receptive fields in cat striate cortex. J Neurophysiol 58:1212-1232.

Kawaguchi Y (1993) Groupings of nonpyramidal and pyramidal cells with specific physiological and morphological characteristics in rat frontal cortex. J Neurophysiol 69:416-431.

Kawaguchi Y, Kubota Y (1993) Correlation of physiological subgroupings of nonpyramidal cells with parvalbumin- and calbindinD28kimmunoreactive neurons in layer $\mathrm{V}$ of rat frontal cortex. J Neurophysiol 70:387-396.

Lampl I, Anderson JS, Gillespie DC, Ferster D (2001) Prediction of orientation selectivity from receptive field architecture in simple cells of cat visual cortex. Neuron 30:263-274.

Lauritzen TZ, Miller KD (2003) Different roles for simple-cell and complexcell inhibition in V1. J Neurosci 23:10201-10213.

Marino J, Schummers J, Lyon DC, Schwabe L, Beck O, Wiesing P, Obermayer $\mathrm{K}$, Sur M (2005) Invariant computations in local cortical networks with balanced excitation and inhibition. Nat Neurosci 8:194-201.

Martinez LM, Alonso JM, Reid RC, Hirsch JA (2002) Laminar processing of stimulus orientation in cat visual cortex. J Physiol (Lond) 540:321-333.

McCormick DA, Connors BW, Lighthall JW, Prince DA (1985) Comparative electrophysiology of pyramidal and sparsely spiny stellate neurons of the neocortex. J Neurophysiol 54:782-806.

Miller KD (2003) Understanding layer 4 of the cortical circuit: a model based on cat V1. Cereb Cortex 13:73-82.

Miller KD, Troyer TW (2002) Neural noise can explain expansive, powerlaw nonlinearities in neural response functions. J Neurophysiol 87:653-659.

Monier C, Chavane F, Baudot P, Graham LJ, Fregnac Y (2003) Orientation and direction selectivity of synaptic inputs in visual cortical neurons: a diversity of combinations produces spike tuning. Neuron 37:663-680.

Murphy BK, Miller KD (2003) Multiplicative gain changes are induced by excitation or inhibition alone. J Neurosci 23:10040-10051.

Nelson S, Toth L, Sheth B, Sur M (1994) Orientation selectivity of cortical neurons during intracellular blockade of inhibition. Science 265:774-777.

Nowak LG, Azouz R, Sanchez-Vives MV, Gray CM, McCormick DA (2003) Electrophysiological classes of cat primary visual cortical neurons in vivo as revealed by quantitative analyses. J Neurophysiol 89:1541-1566.

Porter JT, Johnson CK, Agmon A (2001) Diverse types of interneurons generate thalamus-evoked feedforward inhibition in the mouse barrel cortex. J Neurosci 21:2699-2710.

Prescott SA, De Koninck Y (2003) Gain control of firing rate by shunting inhibition: roles of synaptic noise and dendritic saturation. Proc Natl Acad Sci USA 100:2076-2081.

Priebe NJ, Ferster D (2006) Mechanisms underlying cross-orientation suppression in cat visual cortex. Nat Neurosci 9:552-561.

Priebe NJ, Mechler F, Carandini M, Ferster D (2004) The contribution of spike threshold to the dichotomy of cortical simple and complex cells. Nat Neurosci 7:1113-1122.

Rall W (1957) Membrane time constant of motoneurons. Science 126:454.

Ringach DL, Hawken MJ, Shapley R (2003) Dynamics of orientation tuning in macaque V1: the role of global and tuned suppression. J Neurophysiol 90:342-352.

Skottun BC, Bradley A, Sclar G, Ohzawa I, Freeman RD (1987) The effects of contrast on visual orientation and spatial frequency discrimination: a comparison of single cells and behavior. J Neurophysiol $57: 773-786$. 
Sohya K, Kameyama K, Yanagawa Y, Obata K, Tsumoto T (2007) GABAergic neurons are less selective to stimulus orientation than excitatory neurons in layer $2 / 3$ of visual cortex, as revealed by in vivo functional $\mathrm{Ca}^{2+}$ imaging in transgenic mice. J Neurosci 27:2145-2149.

Somers DC, Nelson SB, Sur M (1995) An emergent model of orientation selectivity in cat visual cortical simple cells. J Neurosci 15:5448-5465.

Spencer WA, Kandel ER (1961) Electrophysiology of hippocampal neurons. III. Firing level and time constant. J Neurophysiol 24:260-271.

Swadlow HA (1995) Influence of VPM afferents on putative inhibitory interneurons in S1 of the awake rabbit: evidence from cross-correlation, microstimulation, and latencies to peripheral sensory stimulation. J Neurophysiol 73:1584-1599.

Troyer TW, Krukowski AE, Priebe NJ, Miller KD (1998) Contrast-invariant orientation tuning in cat visual cortex: thalamocortical input tuning and correlation-based intracortical connectivity. J Neurosci 18:5908-5927.

Usrey WM, Sceniak MP, Chapman B (2003) Receptive fields and response properties of neurons in layer 4 of ferret visual cotex. J Neurophysio 89:1003-1015.

Wehr M, Zador AM (2003) Balanced inhibition underlies tuning and sharpens spike timing in auditory cortex. Nature 426:442-446.

Wilent WB, Contreras D (2005a) Stimulus-dependent changes in spike threshold enhance feature selectivity in rat barrel cortex neurons. J Neurosci 25:2983-2991.

Wilent WB, Contreras D (2005b) Dynamics of excitation and inhibition underlying stimulus selectivity in rat somatosensory cortex. Nat Neurosci $8: 1364-1370$ 